\title{
Practice and Reflection on Interactive Three-Dimensional Teaching System in Agricultural and Forestry Colleges
}

\author{
Zhimin Lei ${ }^{1}$ \\ ${ }^{1}$ College of Politics, Sichuan Agricultural University, Chengdu, China \\ Correspondence: Zhimin Lei, College of Politics, Sichuan Agricultural University, Chengdu 611130, China. \\ E-mail: zhiminlei2007@163.com
}

Received: Kanuary 6, 2013

Accepted: January 10, 2013

Online Published: February 25, 2013

doi:10.5539/ies.v6n3p221

URL: http://dx.doi.org/10.5539/ies.v6n3p221

Sponsored by Joint Association of Social Sciences in Sichuan Agricultural University

\begin{abstract}
Ever since the new curriculum was implemented, Sichuan Agricultural University that is characterized by agricultural science has conducted ideological and political teaching reform, explored a basic route to integrate scientific outlook on development into theoretical teaching and initially formed a human-oriented interactive three-dimensional teaching system. In the practice of teaching reform, this university has insisted on healthy growth orientation of students and the basic principle of respecting students' subjective status, stuck to the basic principle of the guiding position of Marxism and the leading position of students, set up the board of studies mechanism to direct students to take an initiative in participating in reform on theoretical teaching, constructed the self-education module of interaction of "explaining the theory" by students, set up the subjective teaching module of teaching leading and interaction between teachers and students and gradually formed the "quaternity" interactive teaching mode in which the four aspects of teachers and students, students and students, intracurricular and extracurricular resources and practice of students inside and outside the school interact with each other in an organic way. The result of the teaching reform practice is of demonstrative significance and promotion value.
\end{abstract}

Keywords: institution of higher learning, Sichuan Agricultural University, human oriented, interactive three-dimensional teaching system, teaching reform

\section{Introducation}

Ever since the new curriculum was implemented, guided by the scientific outlook on development, Sichuan Agricultural University has positively conducted Marxism theoretical teaching reform and has initially formed the interactive three-dimensional classroom teaching system. It is indicated by the practice that the teaching reform has improved the quality of theoretical classroom teaching and has complied with the times requirements of the new century and the new era for innovation of ideological and political education reform among university students.

\section{The Teaching Idea of Interactive Three-Dimensional Teaching System}

In the university campus under attack of diversified thoughts, the university students whose outlook on life, outlook on world and value concept are at an important period of formation are still ambiguous about such important theories on how to have a correct idea about the path of socialism with Chinese characteristics, and how to make a clear distinction consciously between Marxism and anti-Marxism and democracy of socialism with Chinese characteristics and democracy of western capitalism and between socialism thinking culture and feudalism and capitalism decadent ideological culture, etc. Confusion of university students in terms of thought and political perplex are directly reflected in the theoretical teaching classroom of ideological and political educational battlefield. Quite a large proportion of university students are indifferent to and even disgusting about the ideological and political theoretical classes and skip classes with all sorts of reasons, having a high rate of class skipping.

According to the survey, the rate of skipping professional classes in institutions of higher learning is approximately $20 \%$, the rate of skipping basic classes is more than $25 \%$ and the rate of skipping ideological and 
political education classes is as high as $50 \%$ (Huang Xian \& Dong Xiaofang, 2007). Even if some students do not skip classes, they "live in the Cap camp but their heart is in the Han camp", and they read newspapers, listen to music, send a short message or sleep in the class. This research has conducted a questionnaire survey for four times consecutively on the problems of university students, such as, "Would you choose it if the ideological and political education class is a compulsory class? What is the reason?", etc. It is indicated through the survey that, the choice of students is amazingly similar. The students who volunteer to choose the ideological and political education class account for less than $30 \%$ and the reasons why they do not choose the class is that this class is "bald", "indoctrinating" and "mechanical memorizing", etc.

This result alerts that the ideological and political education has to be close to the fundamental task of "what kind of people to cultivate and how to cultivate people", intensify the strength of ideological and political education, especially classroom teaching reform, follow the human-oriented educational rule according to the cognitive characteristics of contemporary university students, insist on and improve the knowledge cultivation and capacity cultivation system that has the primary task of cultivation of value concept, innovate classroom teaching mode, guide university students to have a correct idea about the theory of "four significant boundaries" and the realistic problems, consciously resist invasion of feudalism and capitalism as well as all kinds of wrong decadent thoughts, go against "westernization" and "polarization" of western powers, practically enhance the teaching level of political theory classroom in institutions of higher learning and ensure that ideological and political education will be effective through reform on teaching.

Human orientation is the core and essence of scientific outlook on development. Orientation of healthy growth of university students is the starting point and objective of ideological and political education in institutions of higher learning. At the national education job conference, Chinese President Hu Jintao pointed out that "insisting on human orientation and overall implementation of quality-oriented education is the strategic subject of education reform and development and is the requirements of the times to carry out the educational policy of the Communist Party of China. The core is to resolve such important problems as what kind of people to cultivate and how to cultivate people. The focus is to facilitate overall development of all university students, put forth all efforts to enhance the social sense of responsibility of university students to serve the country and serve the people, the innovative spirit of students to have the courage to make new explorations and the practical ability to resolve all sorts of problems, guide students to form correct outlook on world, outlook on life and value concept, stabilize students' belief and confidence in leadership of CPC and the socialism system." (Hu Jintao, 2010)

Institutions of higher learning are the important battlefield for study on Marxism theory, subject construction and cultivation of talents and are also an important target for penetration of western hostile forces. In order to firmly grasp the initiative of CPC in the ideological work, it is necessary to strengthen ideological and political education.

"State Planning Outline for Medium and Long-term Education Reform and Development" clearly defines "persistence of belief and excellence of morality" as the primary standard for high quality and professional talents and topnotch and innovative talents, which highlights that moral education is the first. At present, there are approximately a number of more than 23 million junior college students, undergraduates and postgraduates. "Their quality, especially their political quality and whether they are qualified to become the qualified constructors and reliable successors of the socialism career with Chinese characteristics concerns whether the career of CPC has qualified successors and whether the nation has the lasting political stability and concerns whether the magnificent target of building a well-off society in an all-round way and the great rejuvenation of the Chinese nation can be fulfilled". (Li Weihong, 2006)

It is the core of ideological and political education reform to integrate the scientific outlook on development into ideological and political education and to realize maximization of efficiency of ideological and political education in an organic way. In the practice of teaching reform, Sichuan Agricultural University has insisted on the working thought of close combination of cultivation of knowledge and capacity and cultivation of value concept, gradually formed the "quaternity" interactive teaching idea of organic interaction of the four aspects of teachers and students, students and students, intracurricular and extracurricular resources and practice of students inside and outside the campus and initially set up the interactive three-dimensional teaching mode characterized by "one center and two basic points".

\section{The Two Footholds for Interactive Three-Dimensional Teaching System}

\subsection{Persistence in the Foothold of Student Orientation}

With continuous expansion of opening the domestic door to the outside world and further development of socialist market economy, the economic components, organizational patterns, employment modes, interest 
relationship and distribution modes of the society are diversified, independence, choice, variation and difference of university students' thinking activities become significantly intensified and the value concepts of university students present a tendency of increasing diversification and complexity.

University students are the object of ideological and political education and are also the subject of ideological and political education. As is well known to all, the essence of ideological and political education is the focus on carrying forward and cultivating the subjectivity of people. According to Marx, "human is a particular individual and it is exactly his particularity that makes him become an individual and a realistic and single social existence. Likewise, he is also a general whole of concept and the society that is reflected and perceived is the self existence of the subject. Just as he exists as the intuition of a social being and the realistic share in reality, he also exists as a whole of human life". (Karl Marx and Frederick Engels, 1979) In the contemporary world, approaching of the knowledge economy and construction of the harmonious society call for the full playing and development of subjectivity of human. "In order for ideological and political education to adapt to the need of the times, it is necessary to give full play to its particular role in development of subjectivity of human being." (Wang Xuejian, 2008)

The subjectivity role of students is to base on students themselves. Theoretical teachers are required to really set up the idea of student orientation, take an initiative in communicating with students in the practice of teaching, go deep into the thinking reality of students, come to know about their interests, demands and confusion of thought, respect their judgment and choice, direct students in accordance with the circumstance and direct students in setting up correct value concept, outlook on world and outlook on life in the learning atmosphere of studying rules and exploring truth.

The subjectivity role of students is to base on students and to require teachers to have the open-minded, democratic and scientific consciousness and change their arbitrary "chief autocracy" style in the classroom. Teachers ought to learn to go off the platform and actively mobilize students' enthusiasm and initiative in participating in education and self-education. Teachers should encourage students to go on the platform, replace the "class ruled by the voice of one alone" with the "class allowing everyone to have his say" which everyone can participate in, resolve problems of students in terms of ideological knowledge at an equal and rational atmosphere, lead students in setting up correct value concept and outlook on world, cultivate the materialist dialectic thinking of students in the process of learning, teach them to learn to correctly grasp the social development rules and help them improve their ideological knowledge and enhance their ideological state in the process of resolving their ideological confusion.

The subjectivity role of students is to start out from the ideological reality of students with the essence of students orientation, start out from resolving students' ideological confusion, start out from the current cognitive structure and cognitive rules of students, customize an effective theoretical learning and research plan for students and fulfill the ultimate goal of healthy growth of students and facilitating students' overall development of ideological and moral quality.

Student orientation is the foundation for construction of the new "quaternity" interactive teaching system and is also the essence for formation and development of ideological and political education and self-education in theoretical class.

\subsection{Persistence in the Foothold Directed by Marxism and Led by Teachers}

The Chinese President Hu Jintao pointed out, "Education should insist on education orientation and moral education first and regard establishing morality and educating people as the fundamental task of education. It is necessary to strengthen patriotism education, carry out in a deep-going way the ideological belief education, intensify and improve the ideological and political work of students, integrate the core value system of socialism into the national education, direct students in setting up correct outlook on world, outlook on life and value concept and try to cultivate socialism constructors and successors with all-round development of morality, intelligence, physique and aesthetic." (Hu Jintao, 2007) Thus, university student orientation in the ideological and political education and teaching is not to let teachers stay in the dry tree and give up the leading position in ideological education and teaching and not to give up the guiding position of Marxism and let gone unchecked any wrong train of thought overflow in the theoretical classroom, but to intensify the guiding position of Marxism and leading position of teachers.

The teachers of ideological and political theory class are not common knowledge lecturers, but more are "lecturers of Marxism theory and the route and policy of CPC and the disseminators of socialism ideological pattern and spiritual civilization". Thus, they are supposed to become a model of "solid Marxism followers who impart knowledge and educate people and the director and guide of healthy growth of university students." 
In order to insist on the guiding position of Marxism and leading position of teachers, the first thing to do is to strengthen the education and teaching idea of education orientation and moral education first among theoretical teachers. Only when teachers possess strong ideological sentiment of imparting knowledge and educating people as well as setting up morality, have correct value concept, outlook on life, outlook on world and concept of honor and dishonor educational consciousness, and apply them into and reflect them in the daily education and teaching, can they persist in the guiding position of Marxism and the leading position of teachers.

Then, it is necessary for teachers to intensify their own Marxism theoretical sentiment, to be good at applying the basic standpoint, viewpoint and method of Marxism, to combine theoretical and practical problems and historical and realistic problems, to cultivate students' thinking and analytical ability to know about the history and recognize the reality in a scientific way and to help them correctly understand that the development path of socialism with Chinese characteristics is the direction of rejuvenation of China and firmly confirm that the Communist Party of China is the belief of the core leadership for the national rejuvenation.

In order to insist on the guiding position of Marxism and the leading position of teachers, teachers are required, in terms of teaching methodology, to have the capacity of developing and applying the educating function of education and teaching content. Teachers are required to take into consideration the goal of education and teaching, penetrate the four major aspects and spiritual essence of the core value system of socialism into the curriculum system, set up rational teaching knowledge structure of the core value system of socialism, reform and innovate the teaching mode on the basis of combining new achievements of the teaching theory and further understanding students, combine in an organic way the diversification of teaching means and the leading role of ideological education, stimulate students' initiative and enthusiasm in education and self-education, changing the profound theory into straightway life guide and enable the scientific theory to be internalized into correct outlook on life, value concept and outlook on world of university students and to be externalized into the realistic life and social practice action.

\section{The Central Aspects of Interactive Three-Dimensional Teaching System}

Some foreign academics believe that "any society may successfully imbue its social members with the thought suitable for them to maintain their system in order to survive" (Alolaim, 1989) since stability of a political system is derived from the condition of political culture and ideology.

Under the great background of contemporary economic globalization and diversification of social thoughts, the great performance of the ideological function of socialism with Chinese characteristics is "to start out from effectiveness of ideological and political education, try all possible means to strengthen the cohesive force of the CPC and the nation and to maintain social stability". (Wang Xuejian, 2008) Sichuan Agricultural University initially set up the "quaternity" interactive three-dimensional teaching system at the beginning of the teaching reform practice. The university set up a three-dimensional platform of ideological and political education and self-education of students by combining the four major aspects of interaction between teachers and students, interaction between students and students, intracurriculur resource and extracurricular resources and activities inside and outside the university and highlighted the pertinence and effectiveness of ideological and political education.

\subsection{To Build up the Platform for Students to Actively Participate in the Theoretical Learning}

The interactive three-dimensional classroom teaching system insists on the policy of students orientation and teachers' scientific guidance, pays attention to "knowing about students' need, interest and aspiration, respecting students' value judgment and choice and directing students to set up correct value concept in accordance with the social requirements and the physical and psychological development rule of human beings" (Zhao Yetian, et al, 2010) and establishes a theoretical board of studies mechanism.

Under guidance of teachers, the board of studies is constituted by the commissaries in charge of studies in different classes. The working mechanism of the board of studies is that, the commissaries in charge of studies in different classes hold the position of the rotating chairman, all the classes work in cooperation with a due division of the board work, preside over the speech prior to the class, take responsibility for questionnaire survey before and after the class, collect and sort out those realistic ideological and theoretical problems that students are generally confused about and take part in and organize the speech prior to the class, keynote speech and presentation and assessment of course paper, etc. The board of studies is subordinate to the guidance of the theoretical teachers and collects the ideological condition and information feedback of the vast majority of university students, so it becomes an effective channel and ideological collision resonance point for communication of educators and educatees. In the meantime, under the guidance of teachers, the board of studies refines the realistic ideological knowledge problems, the purpose of ideological and political education and 
teaching and realistic significance rights and wrongs that students are relatively unanimous in terms of ideological cognition, determines the theme of discussion and means of implementation and promotes pertinence and efficacy of education. Thus, the board of studies becomes the organization guarantee for effective implementation of the "quaternity" interactive three-dimensional classroom teaching.

\subsection{To Build up the Platform of Interactive Self-Education among University Students}

At the new century, university students have possessed a lot of theoretical quality and learning experiences and they have strong consciousness of subjectivity, participation and self-consciousness. "I want to have a speech" has become the mainstream consciousness for the contemporary university students. The theoretical learning in universities is aimed for the young group of students whose ideology is developed towards rationality and maturity and who are in urgent need of theoretical navigation. In order to fulfill effectiveness from ideological persuasion to ideological direction in limited theoretical learning, a variety of interactive teaching activities and experiments among students that "I want to teach the theory" are conducted in classroom teaching.

For example, the speech mechanism of "ten minutes prior to the class" is established, which is constituted by the two parts of "today in the modern and contemporary Chinese history" and "current events commentation". The commissary in charge of studies in each class calls for students in the class to form a group to offer dynamic management in terms of participation personnel, speech theme and speech pattern, etc. The necessary flow is that students put forward questions which are finally evaluated and summarized by teachers. The speech theme is determined by the theme of teaching and the current hot political issues. Students from the College of Animal Science and Technology in Sichuan Agricultural University in the grade of 2008 made a questionnaire survey on students in the grade of 2007 and in the grade of 2008 who had participated in three-dimensional teaching reform and there were $61.11 \%$ of students who had a positive opinion on the forum of "ten minutes prior to the class".

For example, the interactive mechanism of "I want to have a class" is established. Students participate in the mechanism in the form of a group (lecturer and participant), offer multi-media means and stimulate class discussion with group discussion. The duration of time was 20 minutes. The discussion was arranged for once to twice for one school semester. We had a theme speech on "building the country with negotiation" and students participated in the discussion actively. Teachers assisted students in providing them with relevant online data and students worked out a multimedia courseware in the form of a group and explained with excellent voice and affection and manifested a heartshaking multimedia presentation, which received high appreciation from other students. They also planned the forum subjects of "Long March and belief", "building the country with negotiation", "combating corruption and upholding integrity" and "China and the World Expo", etc. by combining the important current political issues of the $60^{\text {th }}$ anniversary of building the country, holding the 4th Plenary Session of the 17th Central Committee of the CPC and the World Expo and considering the teaching plan. The students all had a positive response. A series of students' self-education activities that "I want to teach the theory" has realized the teaching experience of interaction, mutual teaching and mutual reflection among students and has received a good ideological and political education and teaching effect.

\subsection{To Build up the Platform of Subjective Teaching with Combination of Teacher Leading and Student Participation}

Ideological and political theory learning in universities should neither advocate solo by teachers nor let students go unchecked. Instead, the ideological and political theoretical learning should advocate playing in union by wind music and string music and soaring of the theme.

It is pointed out in "State Planning Outline for Medium and Long-term Education Reform and Development", teaching should focus on combination of learning and reflection. It advocates heuristic method, inquiry based method, discussion based method and participative teaching method to assist students in learning to learn. And it also advocates building up a perfect environment in which one can reflect independently, explore freely and be brave enough to make innovation. Thus, teaching reform ought to try to build up an interaction based teaching module with organic combination of teachers' theoretical teaching and students' participation in discussion according to the cognitive characteristics of students and the features of the subjects.

The overall train of thought in interactive teaching of teachers and students is that, teachers get a scientific mastery of implementation of education content and application of teaching means in accordance with the principle of education effectiveness and take organic control over the breadth and depth of interaction among teachers and students. First of all, it is necessary for teachers to decide a theme for the class before they start the class, announce relevant issues and data and let students make preparations for discussion. The teachers are supposed to arrange the proportion of time of teaching and time of discussion in a rational way, take the basic path of teaching and education goal $\rightarrow$ proposing a topic $\rightarrow$ directing students in thinking $\rightarrow$ encouraging 
students to have a speech $\rightarrow$ initial conclusion by teachers $\rightarrow$ in-depth discussion of the topic $\rightarrow$ evaluation and summary by teachers and try to build up a theoretical learning atmosphere in which everyone actively reflects and speaks out freely. Considering the specific teaching goal, teachers concentrate on question-based teaching, design relevant interlinking problems in the process of teaching and direct students get close to the education goal step by step by means of reflection and discussion on relevant problems.

Then, it is necessary to make full use of the multimedia facilities and advocate students in working in cooperation with a due division of work in the form of a small group and participating in discussion. It is advocated that teachers go off the platform, walk into the group of students, have a face-to-face communication with students, encourage students to actively participate in discussion, give directions to students in due course, resort to an appropriate opportunity to guide students and let the magic of theory penetrate into the heart of students just as the wind diving into the night and moistening everything silently. It is indicated by practice that, the interactive teaching among teachers and students with combination of teacher teaching and students discussion has received high appreciation from students. Students in the Agricultural Major in the grade of 2008 in Sichuan Agricultural University made a survey report which held the opinion that is was not enough just to rely on teaching by teachers in the classroom and students were also required to participate in the classroom. Only if students participate in the classroom, can teachers cultivate their interest and can the classroom really play its role of education. Thus, the universities also should open more discussion classes and practical classes.

4.4 To Build up the Platform of Teaching Practice with Combination of Intracurricular Education and Extracurricular Current Events and Hot Issues

Intracurricular and on-campus education is mainly "education on students with the method of construction of theoretical or knowledge logic" and is "a sort of educational channel that can most concentratively reflect the content of ideological and political education" (She Shuanghao, 2010); extracurricular and after-school education is mainly a sort of education which regards the practical activities of students as the subject. The era of reform and opening up offers a lot of fresh social education resources that are of great development value for university theoretical education and teaching. Thus, an organic combination of intracurricular education and extracurricular education will be an important approach to realize effectiveness of ideological and political education in universities. Yet, it is necessary to take a grasp of the combination point of the two in order to integrate the two in an organic way.

In the practice, it is discovered that to grasp the point of combination is to be good at grasping education opportunities. That is to say, it is necessary to grab the anniversary of significant social activities as the point of penetration, highlight ideological and political education theme and look for opportunities to resolve the ideological understanding of students and significant theoretical issues. In the process of teaching reform, it is likely to resort to such hot issues of current affairs as World Expo, holding of the $17^{\text {th }}$ Party Congress and the $60^{\text {th }}$ anniversary of building the country and so on to conduct extracurricular practical teaching activities, realize ideological direction through education and self-education practical activities among students, improve their concepts, enhance their knowledge and promote efficiency and maximization of the educating function of both intracurricular and extracurricular educational resources.

For instance, in the $60^{\text {th }}$ anniversary of building the country, the teachers taught with emphasis the key teaching class of "pioneering of the new path for Chinese revolution", assigned the course paper of "Long March and belief" and recommended conducting the observation activity of "re-walking the path of Long March" in the National Day Holiday. Students in the Bioscience major in the grade of 2006 organized a squad, walked towards Luding Bridge across Dudu River by means of taking a bicycle and followed the trace of the Red Army. With the social practical activities as the platform, the squad conducted the speech activity prior to the class with the subject of "belief", gave an enthusiastic speech according to their own experiences and deeply moved the vast majority of teachers and students. It was generally believed, we had almost slipped the significant mission in front of us out of our memory maybe because our life had been too peaceful. The Red Army had fought for the new China and we are supposed to fight for a prosperous and powerful China.

\section{References}

Alolaim. (1989). Introduction to Political Sociology, translated by Dong, Yunhu \& Li, Yunlong. Zhejiang People's Publishing House, p. 365.

Central Compilation \& Translation Bureau. (1979). Karl Marx and Frederick Engels. People’s Publishing House, $42,123$.

Hu, Jintao. (2007). Talk of President Hu Jin-tao in the National Excellent Teachers Symposium. People's Daily, 
September 1 .

Hu, Jintao. (2010). Speech at the National Education Conference. People's Daily, July 14.

Huang, Xian, \& Dong, Xiaofang. (2007). Why University Classroom Lacks Attraction? People's Daily, May 24.

Ideological Education Department of the Ministry of Education. (2005). Opinions of Propaganda Department of the Communist Party of China and Ministry of Education to Furniture Strengthen and Improve Ideological and Political Theoretical Class in Institutions of Higher Learning, in Major Selected Literature on Strengthening and Improving the Ideological and Political Education among University Students (1978-2008). China Renmin University Press Co., February 7, p.420.

Li, Weihong. (2006). Carrying Out Successfully the New Scheme of Ideological and Political Theory Education by Reaching Common Understanding, Clarifying Our Tasks, and Doing Solid Work. Journal of Ideological \& Theoretical Education, supplement, 2-12.

She, Shuanghao. (2010). Closely Combine Classroom Education with Extracurricular Education. Theoretical Front in Higher Education, 8, 24-25.

Wang, Xuejian. (2008). Study on Frontier Issues of Modern Ideological and Political Education. People's Publishing House, 405, 411.

Zhao, Yetian et al. (2010). Closely Combine Training of Knowledge, Ability with Education of Values. Theoretical Front in Higher Education, 8(23). 